\title{
Analysis on Spatial-Temporal Evolution of Ecological Carrying Capacity in Greater Bay Area Around Hangzhou Bay
}

\author{
Qiyuan Wei \\ College of Architecture and Environment, Sichuan University, Chengdu, China \\ 2018141472004@stu.scu.edu.cn
}

\begin{abstract}
The Great Bay Area around Hangzhou Bay is the intersection of multiple national strategies the coastal open zone, the Yangtze River Economic Belt, the Yangtze River Delta urban agglomeration and the Belt and Road Initiative. Ecological carrying capacity is the maximum capacity of an ecosystem to bear human activities on the premise of maintaining its normal operation, which can provide a reference for judging the degree of regional sustainable development and future planning and construction. In this study, the evaluation index system of ecological carrying capacity was constructed based on the PSR model. The spatio-temporal evolution of ecological carrying capacity in the Great Bay Area around Hangzhou from 2006 to 2019 was analyzed using the TOPSIS model, exponential smoothing method and GIS spatial analysis method. The results show that the pressure is carrying capacity generally decreases, and it is predicted to decrease from 2020 to 2022. the state bearing capacity tends to be ideal, and the development prospect is good; response bearing capacity and comprehensive bearing capacity are highly overlapped, reaching the minimum and maximum in 2012 and 2016, respectively; the ecological carrying capacity of cities in the northwest of Hangzhou and Shanghai is in good condition. After the unified planning, the ecological carrying capacity of Jiaxing and other cities has been significantly improved, and the ecological carrying capacity of cities in the bay area is more inclined to balanced development. Combined with the correlation analysis, it is concluded that the proportion of fixed assets investment in the construction of landscaping public facilities in GDP is the key factor restricting the comprehensive carrying capacity. The research results are of great significance to formulating policies for sustainable socioeconomic development in the Bay Area.
\end{abstract}

Keywords: Ecological Carrying Capacity; Hangzhou Greater Bay Area; PSR Model; TOPSIS Model; GIS.

\section{Introduction}

With the rapid development of the economy in today's society, especially the acceleration of industrialization, ecological problems such as resource shortage, ecological degradation and environmental pollution emerge endlessly. The pressure on resources and the environment brought by economic and social development in some regions has exceeded the maximum external load that the ecosystem can bear, resulting in further deterioration of resources and the environment. The Greater Bay Area around Hangzhou Bay is an important bay area economic circle under planning. How to balance the relationship between development and ecological carrying capacity is an important issue in its future construction.

Ecological carrying capacity is one of the important indicators to measure the sustainable development of the economy and society [1]. In the eighteenth century, the British scholar T.R.Malthus put forward the population theory Pierre F. Verhulst used the population growth logistic mathematical equation to lay the foundation for the ecological carrying capacity [2-3]. In 1921, Park and Burgess introduced the concept of carrying capacity into ecology for the first time to characterize the maximum number of a biological individuals under a specific environmental condition[4]. The current ecological carrying capacity can be defined as the threshold that the ecosystem can withstand the impact of human activities on it under the premise of maintaining its own dynamic balance. From a systematic point of view, ecosystems include resource systems and environmental systems[5]. The development of environmental problems has led to a gradual increase in human attention to the carrying capacity, and related research has become increasingly rich. The carrying capacity-related 
research has gradually combined the resource carrying capacity and environmental carrying capacity and developed into a more comprehensive evaluation of ecological carrying capacity [6].

The evaluation methods of ecological carrying capacity include analytic hierarchy process, fuzzy analysis, comprehensive evaluation method, system dynamics model and so on [7]. In recent years, the Evaluation of ecological carrying capacity in China and abroad mainly focuses on three aspects. (1) In space, it is refined from a national scale to a regional or watershed scale. For example, Yue et al. [8] used the state space method to estimate and compare the two urban agglomerations in Liaoning Province; Yue Dongxia et al. [9] calculated the ecological carrying capacity by taking Shule River Basin and the counties under its jurisdiction as different scales and taking the ecological water demand of the basin as the mainline. (2) In terms of time, from the static analysis of a single year to the dynamic analysis and future prediction with period, for example, Cai Fei et al. [10]calculated the ecological footprint, ecological carrying capacity and ecological deficit of Xi 'a City from 2010 to 2018 based on the ecological footprint theory; in addition to the current situation evaluation, Peng et al. [11] used the grey model to predict the development trend of ecological footprint in the urbanization process of the Yangtze River urban accumulation from 2018 to 2022. (3) In terms of application, some scholars have carried out ecological security evaluation research in combination with ecological carrying capacity. For example, Wang et al. [12] pointed out that the carrying capacity in the study area is not enough to support the ecosystem capacity. That is, the ecosystem is in an unsafe state, and the sustainability of economic development cannot be guaranteed.

The bay area is the core urban agglomeration of global economic development and technological innovation. China's gulf area around Hangzhou has a large manufacturing cluster and industrial base, supported by the national ' Belt and Road ' strategy, and plans to be built into a world-class modern gulf area in the future. For the bay area still under planning, the Evaluation of its ecological carrying capacity, on the one hand, meets the inherent requirements of ecological civilization construction, on the other hand, is also conducive to the overall planning, comprehensive coordination and macromanagement of the sustainable development of the regional economy. Therefore, based on the existing research, this paper selects the relevant data from 2006 to 2019, constructs the ecological carrying capacity index system based on the PSR model, and uses the TOPSIS model, exponential smoothing method and GIS spatial analysis method to analyze the temporal and spatial evolution of the ecological carrying capacity of the Hangzhou Bay Area from 2006 to 2019, in order to provide the theoretical basis for the planning and construction and sustainable development of the Bay Area.

\section{Overview of the Study Area}

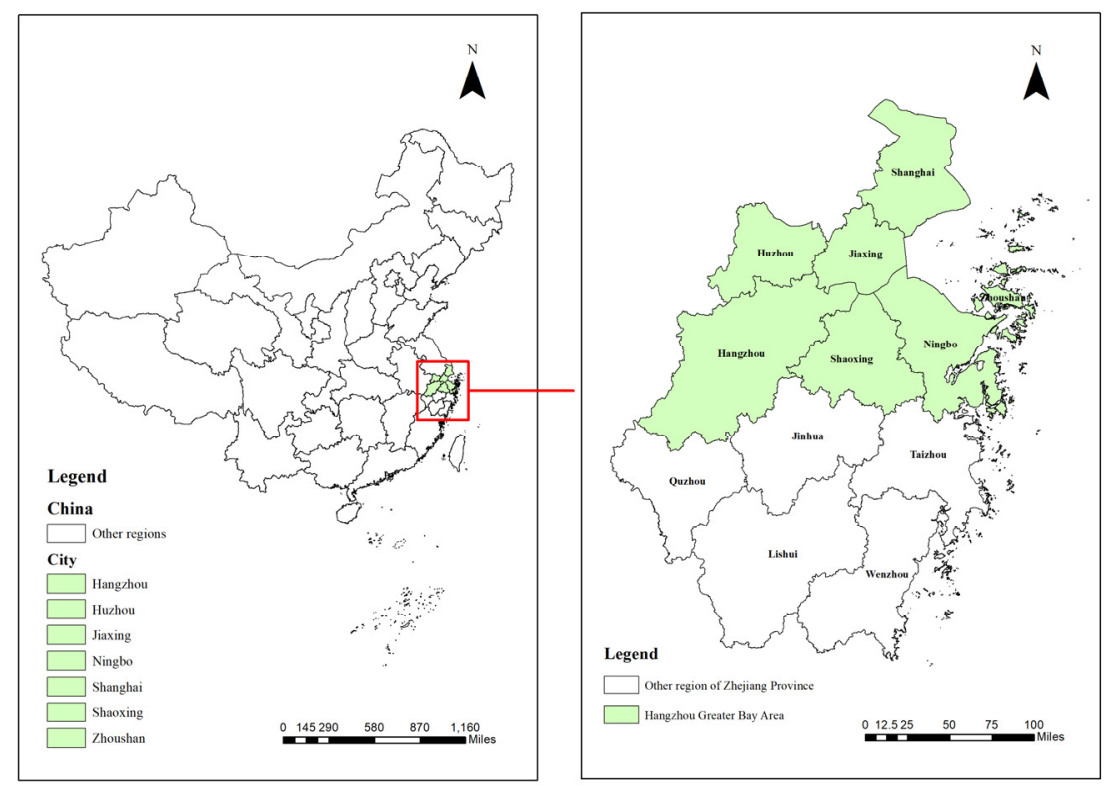

Figure 1. Location map of Hangzhou Greater Bay Area 
The Great Bay Area around Hangzhou Bay is in Zhejiang Province, including Shanghai, Hangzhou, Jiaxing, Huzhou, Shaoxing, Ningbo and Zhoushan. It is mainly subtropical monsoon climate, located in the south of the Yangtze River Delta and the entrance of the Qiantang River, and is the only estuary bay in China. In 2019, the overall area of the Bay Area was about 35174 square kilometers, accounting for less than 0.4 per cent of the country 's land area, but GDP exceeded 8 per cent of the country 's gross domestic product to 8115.8 billion yuan. The Great Bay Area around Hangzhou is a strategically important place for China to promote modernization [13]. Although it is still in planning and construction, it provides good conditions for the rapid development of the economy and society with its unique port, industrial advantages and policy, ecology and talent environment. At the same time, it inevitably poses greater challenges to its ecological carrying capacity.

\section{Research Methods and Data Sources}

\subsection{Data Sources and Index System Establishment}

Table 1. Evaluation Index System of Ecological Carrying Capacity of Hangzhou Greater Bay Area

\begin{tabular}{|c|c|c|c|c|c|}
\hline \multirow[b]{2}{*}{ Aim } & \multirow[b]{2}{*}{ System } & \multicolumn{4}{|c|}{ Index } \\
\hline & & Indicators & Unit & $\begin{array}{l}\text { The nature of } \\
\text { indicators }\end{array}$ & Weights \\
\hline \multirow{17}{*}{$\begin{array}{c}\text { Ecological } \\
\text { Carrying } \\
\text { Capacity }\end{array}$} & \multirow{6}{*}{ Pressure } & Population density & Persons / km2 & - & 0.0930 \\
\hline & & Natural population growth rate & $\%$ & - & 0.0470 \\
\hline & & GDP per capita & $\begin{array}{l}\text { RMB } 10,000 \\
\text { /person }\end{array}$ & + & 0.0683 \\
\hline & & $\begin{array}{c}\text { Industrial } \mathrm{SO}_{2} \text { emission intensity } \\
\text { of } 10000 \text { Yuan GDP }\end{array}$ & Ton & - & 0.0404 \\
\hline & & $\begin{array}{l}\text { The yield of industrial solid waste } \\
\text { of } 10000 \text { Yuan GDP }\end{array}$ & $\begin{array}{l}\text { Ten thousand } \\
\text { tons }\end{array}$ & - & 0.0663 \\
\hline & & $\begin{array}{c}\text { Discharge of industrial } \\
\text { wastewater }\end{array}$ & $\begin{array}{l}\text { Ten thousand } \\
\text { tons }\end{array}$ & - & 0.1326 \\
\hline & \multirow{6}{*}{ State } & Mean temperature & ${ }^{\circ} \mathrm{C}$ & - & 0.0652 \\
\hline & & Precipitation & Millimeter & + & 0.0714 \\
\hline & & Water resources per capita & Cubic metre & + & 0.0772 \\
\hline & & $\begin{array}{l}\text { The proportion of tertiary industry } \\
\text { in GDP }\end{array}$ & $\%$ & + & 0.0836 \\
\hline & & Road area per capita & Square metre & + & 0.0402 \\
\hline & & Effective irrigated area & $\begin{array}{l}\text { Thousand } \\
\text { hectares }\end{array}$ & + & 0.0387 \\
\hline & \multirow{5}{*}{ Response } & Sewage treatment rate & $\%$ & + & 0.0335 \\
\hline & & $\begin{array}{l}\text { The green coverage rate of built- } \\
\text { up area }\end{array}$ & $\%$ & + & 0.0222 \\
\hline & & $\begin{array}{l}\text { The proportion of investment in } \\
\text { fixed assets of urban landscaping } \\
\text { public facilities construction in } \\
\text { GDP }\end{array}$ & $\%$ & + & 0.0576 \\
\hline & & Public park area per capita & Square metre & + & 0.0249 \\
\hline & & $\begin{array}{l}\text { The comprehensive utilization } \\
\text { rate of industrial solid waste }\end{array}$ & $\%$ & + & 0.0380 \\
\hline
\end{tabular}

The PSR (Pressure-State-Response) model is a framework system proposed by the Organization for Economic Cooperation and Development (OECD) and the United Nations Environment 
Programme (UNWP) to evaluate the state of the ecological environment [14], reflecting the interaction between human beings and the environment, as well as the interaction between the natural environment, society and economy, which is now commonly used to evaluate social risks, ecological security, pollution risks, land use and carrying capacity [15]. The PSR model includes three types of indicators, namely, pressure indicator, state indicator and response indicator. Among them, pressure indicators represent the negative impact of human production and living activities on the natural environment, such as resource consumption, pollution emissions; state indicators represent the actual situation of the current natural environment and economic society, such as climate state, per capita social resources and natural resources; response indicators represent the positive measures made by human beings after they realize that their own activities lead to the decline of ecological carrying capacity, such as sewage treatment and greening construction. Indicators are divided into positive and negative indicators, which have a positive or negative impact on the environment as the value of the indicator rises or falls.

Using the PSR model, taking the seven cities in the bay area as the evaluation target layer, taking the pressure, state and response as the three system layers, and selecting 17 indicators from the aspects of environment, economy, society and resources, the ecological carrying capacity evaluation index system of the Great Bay Area around Hangzhou Bay was constructed. There are six pressure layer indexes, six state layer indexes and five response layer indexes, as shown in Table 1. The required original data comes from the relevant public data of each statistical yearbook from 2006 to 2019, such as ' China City Statistical Yearbook' [16], 'China Urban Construction Statistical Yearbook' [17], 'Shanghai Statistical Yearbook' [18], and 'Hangzhou Statistical Yearbook' [19]. The regional administrative boundary vector map comes from the Resource and Environmental Science and Data Center of the Chinese Academy of Sciences [20].

\subsection{Entropy Weight Method}

The entropy weight method is a usual objective weighting method, which depends on the variability of data itself and can eliminate the influence of human factors [21]. The smaller the variation degree of the index is, the less the information reflected is, and the corresponding weight should be lower [22]. Therefore, the entropy weight method needs to standardize the data, then calculate the information entropy of each index, and finally determine its weight. Since the entropy weighting method is relatively mature, the specific process is no longer overstated, and the weight of each index is specified in table 1.

\subsection{Construction of TOPSIS Evaluation Model}

Due to the different dimensions of each index, the original index needs to be normalized first:

$$
a_{p q}^{\prime}=\frac{a_{p q}}{\sqrt{\sum_{q=1}^{n} a_{p q}^{2}}}
$$

In (1), $p=1,2, \ldots, m, m$ is the total number of evaluation years; $q=1,2, \ldots, n, n$ is the total number of evaluation indexes; $a_{p q}$ is the original value of No. $q$ index in No. $p$ year. $a_{p q}^{\prime}$ is the normalized value of No. $q$ index in No. $p$ year.

The obtained results are multiplied by the weights $W_{q}$ obtained by the entropy weight method to construct a standardized weighting matrix $Z$ :

$$
Z=\left[\begin{array}{cccc}
a_{11}^{\prime} \cdot W_{1} & a_{12}^{\prime} \cdot W_{1} & \cdots & a_{1 q}^{\prime} \cdot W_{1} \\
a_{21}^{\prime} \cdot W_{2} & a_{22}^{\prime} \cdot W_{2} & \cdots & a_{1 q}^{\prime} \cdot W_{2} \\
\vdots & \vdots & \vdots & \vdots \\
a_{p 1}^{\prime} \cdot W_{p} & a_{p 2}^{\prime} \cdot W_{p} & \cdots & a_{p q}^{\prime} \cdot W_{p}
\end{array}\right]=\left[\begin{array}{cccc}
z_{11} & z_{12} & \cdots & z_{1 q} \\
z_{21} & z_{22} & \cdots & z_{2 q} \\
\vdots & \vdots & \vdots & \vdots \\
z_{p 1} & z_{p 1} & \cdots & z_{p q}
\end{array}\right]
$$


According to the normalized weighted evaluation matrix to determine the positive and negative ideal solution, so that $Z^{+}$is a positive ideal solution, $Z^{-}$a negative ideal solution, then:

$$
\begin{gathered}
Z^{+}=\left\{\max _{1 \leq q \leq n}\left(z_{p q}\right) \mid i=1,2, \cdots, n\right\}=\left\{z_{1}^{+}, z_{2}^{+}, \cdots, z_{n}^{+}\right\}=\left\{z_{q}^{+}\right\} \\
Z^{-}=\left\{\min _{1 \leq q \leq n}\left(z_{p q}\right) \mid i=1,2, \cdots, n\right\}=\left\{z_{1}^{+}, z_{2}^{+}, \cdots, z_{n}^{+}\right\}=\left\{z_{q}^{-}\right\}
\end{gathered}
$$

The Euclidean distance method is used to calculate the distance between the normative weighting index of each year and their respective positive ideal solution $D_{p}^{+}$and the distance to the negative ideal solution $D_{p}^{-}$:

$$
\begin{gathered}
D_{p}^{+}=\sqrt{\sum_{q=1}^{n}\left(z_{q}^{+}-z_{p q}\right)^{2}} \\
D_{p}^{-}=\sqrt{\sum_{q=1}^{n}\left(z_{q}^{-}-z_{p q}\right)^{2}}
\end{gathered}
$$

In formula (2) (6), $z_{p q}$ is the normalized weighted value of No. $q$ indictor in the No. $p$ year; $\max _{1 \leq q \leq n}\left(z_{p q}\right), \min _{1 \leq q \leq n}\left(z_{p q}\right)$ are the maxium and minium values of the No. $q$ indictor in all years; $z_{q}^{+}$, $z_{q}^{-}$are the positive ideal solution and negative ideal solution of No. $q$ indictor respectively.

Then the closeness $T_{p}$ between the actual ecological carrying capacity and the ideal optimal carrying capacity can be obtained:

$$
T_{p}=\frac{D_{p}^{-}}{D_{p}^{+}+D_{p}^{-}}
$$

In Equation (7), the value range of closeness $T_{p}$ is $(0,1)$. If it approaches 1 , the ecological carrying capacity of this year is ideal; if close to 0 , the ecological carrying capacity is poor.

\subsection{Time Series Prediction}

The exponential smoothing method is a time series prediction method proposed by American mathematician Brown. It can only rely on its existing historical data to predict future data with a short or medium time span[23]. The predicted value obtained by the exponential smoothing method is the result of weighting the data of all years[24]. The farther the time distance is, the smaller the influence on the predicted value is, and the smaller the weight is [25]. In this study, the exponential smoothing method was used to predict the ecological carrying capacity of the bay area from 2020 to 2022 .

\section{Research Results}

\subsection{Comprehensive Analysis of Ecological Pressure-State-Response in the Great Bay Area Around Hangzhou Bay}

The variation trends of pressure-state-response of the ecosystem around Hangzhou Bay with time are shown in Figs. 2 - 4. From 2006 to 2019, the population density and per capita GDP increased year by year, which was close to 1000 people / $\mathrm{km} 2$ and 140,000 yuan in 2019, respectively, indicating that the regional resident population density is increasing, and people's living standards continue to improve. Industrial SO2 emission intensity per ten thousand yuan GDP and industrial solid waste production per ten thousand yuan GDP showed a decreasing trend year by year, indicating that the two pollution levels caused by regional economic activities decreased year by year. The 
natural growth rate of the population and the discharge of industrial wastewater showed a fluctuating rise and fall, respectively. Among them, the population density and its natural growth rate in 2012 had a relatively obvious increase. The reason may be that a new round of small fertility peaks was formed due to the cyclical fluctuation of age structure, and the number of second children in line with the policy increased. Overall, the pressure on the ecological environment in the bay area tends to decrease.
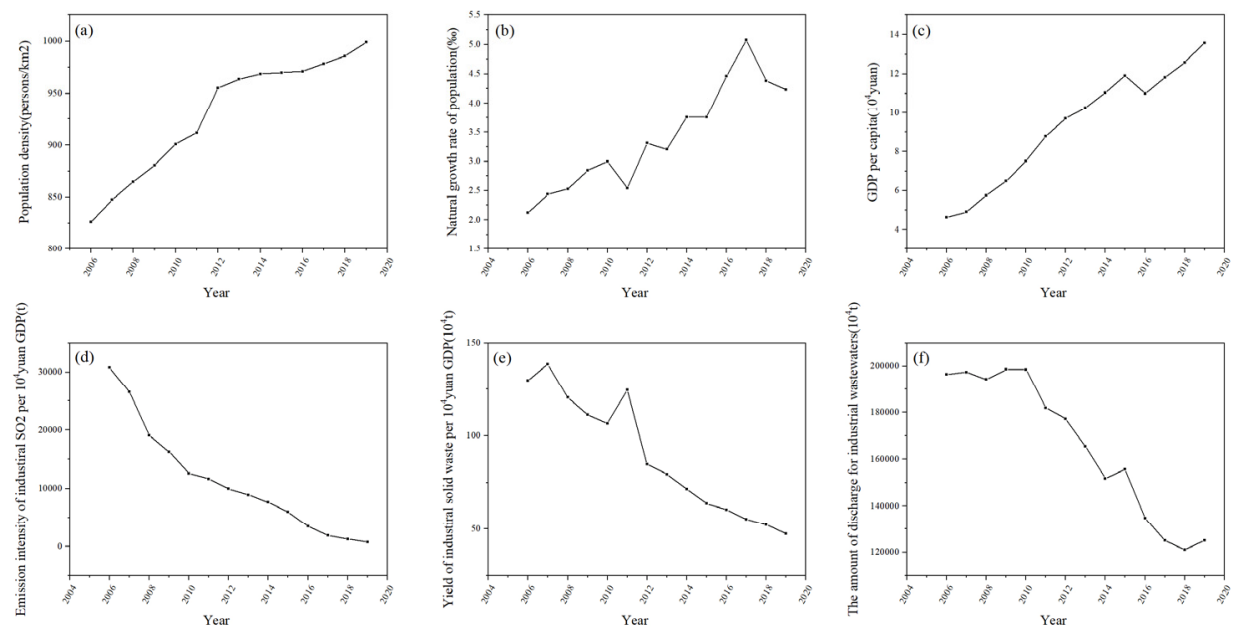

Figure 2. Changes of ecosystem pressure index of Hangzhou Greater Bay Area

For the state level indicators, the proportion of tertiary industry in GDP continues to rise and has exceeded $55 \%$ in 2019, indicating that the economic and social production structure of the Greater Bay Area around Hangzhou Bay has been continuously optimized. Other indexes fluctuated greatly in each year: the average temperature fluctuated between $17{ }^{\circ} \mathrm{C}$ and $18{ }^{\circ} \mathrm{C}$, and the region was generally warm; precipitation is greater than $1000 \mathrm{~mm}$, indicating that the region is relatively humid; per capita, water resources are also fluctuating, the highest is more than $1700 \mathrm{~m} 3$, the lowest is less than $1000 \mathrm{~m} 3$, generally lower than the national average, indicating that the regional per capita water resources are relatively scarce. Per capita road area and effective irrigation area showed relatively small fluctuations in the rise and fall, reflecting the development of urban road infrastructure in the region increased. Still, the degree of agricultural water conservancy decreased. Overall, the ecosystem state of the bay area showed a benign development trend.
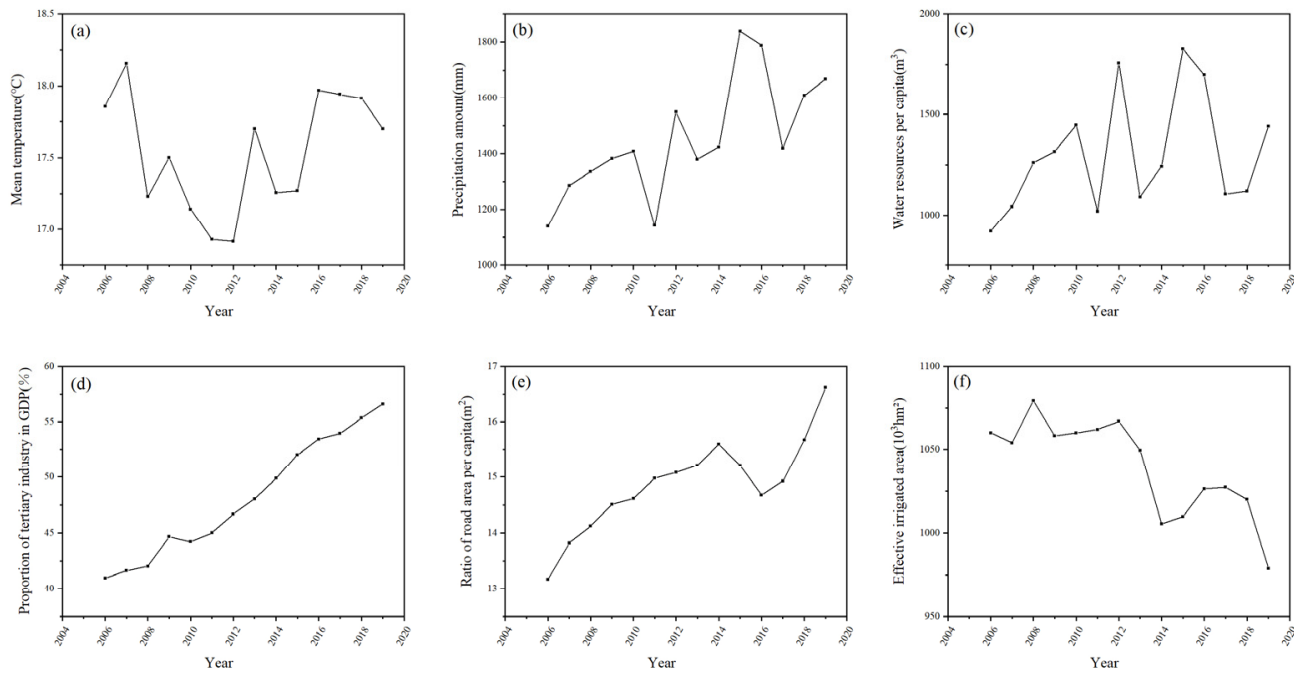

Figure 3. Changes of ecosystem state indicators of Hangzhou Greater Bay Area 
In the response layer indicators, the sewage treatment rate, the greening coverage rate of built-up areas and the per capita public green space area all showed an overall increase trend except for a slight decline in individual years, indicating that the living environment of urban residents was improved. Urban landscape public facilities construction investment in fixed assets accounted for the proportion of GDP fluctuations between $0.1 \%-0.2 \%$, may be affected by the annual government decision-making; The comprehensive utilization rate of industrial solid waste continued to decline after 2014 but resumed growth in 2018, indicating that people's awareness of comprehensive utilization of industrial solid waste has improved in recent years. In general, human responses to the bay area ecosystem have been effective.
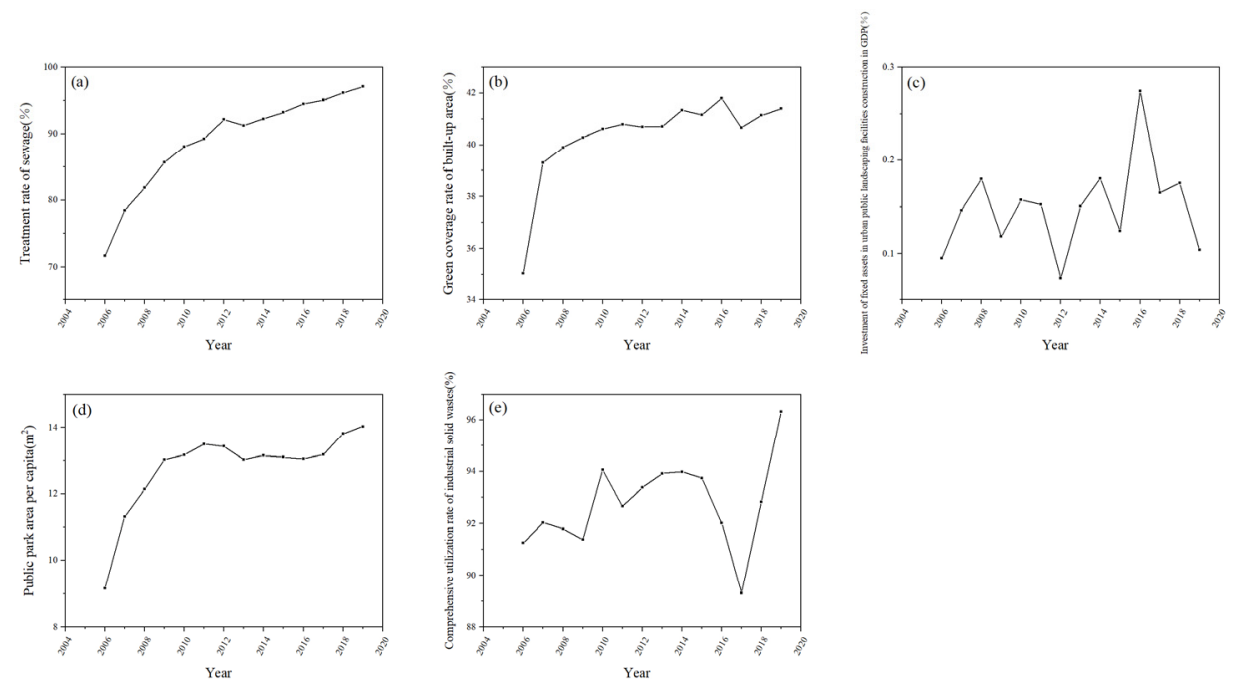

Figure 4. Changes of ecosystem response indexes of Hangzhou Greater Bay Area

\subsection{Time Evolution Analysis of Ecological Carrying Capacity in the Great Bay Area Around Hangzhou Bay}

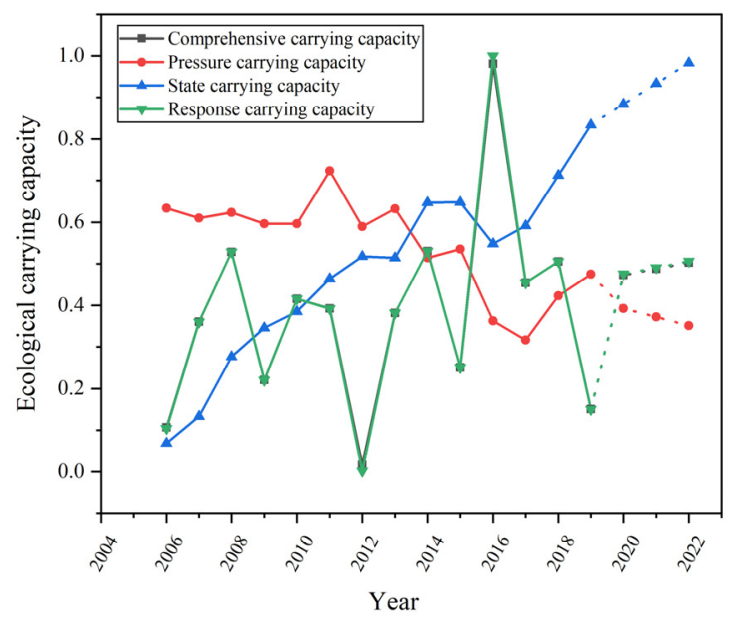

Figure 5. Time-varying point-line diagram of four types of ecological carrying capacity in Hangzhou Greater Bay Area

The specific changes of the ecological carrying capacity of the Greater Bay Area around Hangzhou Bay over time are shown in Figure 5, and the part after the dotted line is the time series prediction result. The results showed that the ecological carrying capacity of the bay area changed significantly from 2006 to 2019. Pressure carrying capacity decreased in fluctuation but rebounded in 2018 and 2019; however, except in 2016, the overall state carrying capacity rose steadily, indicating that the 
state of the regional ecosystem has gradually improved in recent years. It is worth noting that the results and trends of response bearing capacity and comprehensive bearing capacity are highly coincident, and the degree of fluctuation varies from year to year, reaching the minimum and maximum in 2012 and 2016, respectively. From the forecast results of 2020-2022, in addition to the pressure carrying capacity will decline year by year, the other three kinds of carrying capacity are rising steadily, indicating that the ecological carrying capacity of the Greater Bay Area around Hangzhou Bay will gradually improve in the future.

\subsection{Spatial Evolution of Ecological Carrying Capacity in Hangzhou Greater Bay Area}

Taking the calculation results of the ecological carrying capacity of the Greater Bay Area around Hangzhou Bay in 2006,2010,2014, and 2019, ArcGIS software was used to draw its spatial changes, as shown in Figure 6. The shallower the green, the lower the ecological carrying capacity, and vice versa. The higher, the closer to the state of sustainable development. It can be seen from the figure that among all the cities around Hangzhou Bay, Shanghai and Zhoushan had the highest ecological carrying capacity in 2006, while Jiaxing and Hangzhou had the lowest ecological carrying capacity. By 2010, the ecological carrying capacity of cities in the northwest was generally greater than that in the southeast; in 2014, the ecosystem of Jiaxing in the central region and Hangzhou in the southwestern region had relatively poor carrying capacity; By 2019, the distribution of ecological carrying capacity of the whole bay area around Hangzhou Greater Bay Area was relatively uniform, but the ecological carrying capacity of Shanghai was slightly lower than that of other regions. It can be seen that the comprehensive ecological carrying capacity of each city is not the same in the early stage. With the change of time, the northwest city maintains an ideal situation, and the central city is poor. Since the overall comprehensive coordination and macro-management of the managed after planning, the ecological carrying capacity of the bay area tends to be evenly distributed.

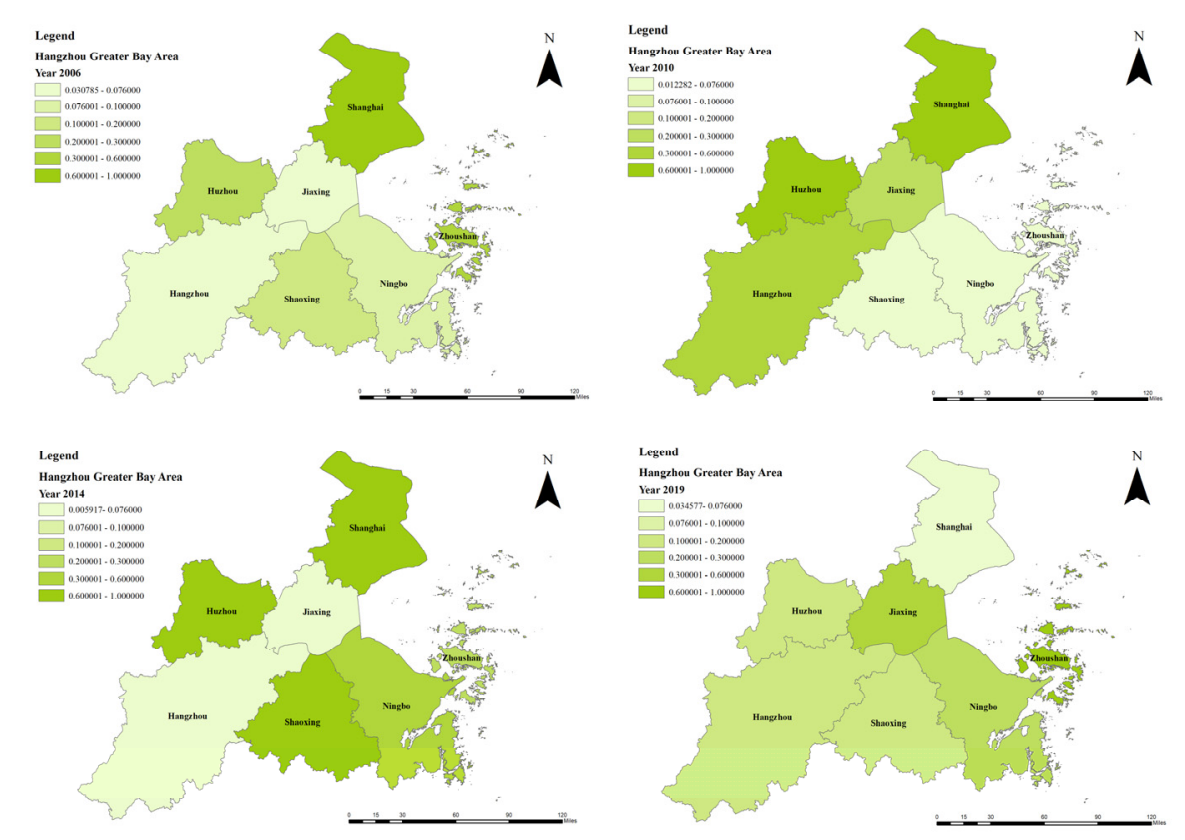

Figure 6. Spatial variation of ecological carrying capacity in Hangzhou Greater Bay Area

\subsection{Driving Factor Analysis of Ecological Carrying Capacity in Hangzhou Bay}

Spearman's two-tailed test was used to analyze the correlation between the ecological carrying capacity and each evaluation index in the Greater Bay Area around Hangzhou Bay, and the correlation coefficient and the significant p-value (i.e., Sig. (two-tailed)) were obtained, as shown in Table 2. It can be seen that the comprehensive carrying capacity of the ecosystem in the Greater Bay Area of Hangzhou Bay is negatively correlated with the five indicators of industrial sulfur dioxide emission 
intensity per ten thousand yuan GDP, industrial solid waste production per ten thousand yuan GDP, industrial wastewater discharge, per capita water resources and effective irrigation area, indicating that the growth of these indicators will reduce the regional ecological carrying capacity. The comprehensive carrying capacity is positively correlated with other 12 indicators such as population density, natural population growth rate, per capita GDP, average temperature, precipitation, the proportion of tertiary industry in GDP, and per capita road area, indicating that the growth of these indicators will improve the regional ecological carrying capacity. It is worth noting that the comprehensive carrying capacity only has a high positive correlation with the proportion of fixed asset investment in urban landscaping public facilities in GDP, and there are significant differences among the samples, that is, there is a very significant positive correlation, indicating that the annual fixed-asset investment in urban landscaping public facilities greatly affects the change of comprehensive carrying capacity.

Table 2. Correlation analysis results of ecological carrying capacity evaluation indicators in the Bay Area around Hangzhou Bay

\begin{tabular}{|c|c|c|c|}
\hline System & Indicators & $\begin{array}{l}\text { Correlation coefficient with } \\
\text { comprehensive bearing } \\
\text { capacity }\end{array}$ & $\begin{array}{l}\text { Sig.(two- } \\
\text { tailed) }\end{array}$ \\
\hline \multirow{6}{*}{ Pressure } & Population density & 0.266 & 0.358 \\
\hline & Natural population growth rate & 0.349 & 0.221 \\
\hline & GDP per capita & 0.200 & 0.493 \\
\hline & $\begin{array}{l}\text { Industrial sulfur dioxide emission intensity of } \\
10000 \text { Yuan GDP }\end{array}$ & -0.266 & 0.358 \\
\hline & $\begin{array}{l}\text { The output of industrial solid waste of } 10000 \\
\text { Yuan GDP }\end{array}$ & -0.253 & 0.383 \\
\hline & Discharge of industrial wastewater & -0.354 & 0.215 \\
\hline \multirow{6}{*}{ State } & Mean air temperature & 0.174 & 0.552 \\
\hline & Precipitation & 0.152 & 0.605 \\
\hline & Water resources per capita & -0.020 & 0.946 \\
\hline & The proportion of tertiary industry in GDP & 0.244 & 0.401 \\
\hline & Per capita road area & 0.081 & 0.782 \\
\hline & Effective irrigation area & -0.209 & 0.474 \\
\hline \multirow{5}{*}{ Response } & Sewage treatment rate & 0.240 & 0.409 \\
\hline & The green coverage rate of built-up area & 0.327 & 0.253 \\
\hline & $\begin{array}{l}\text { The proportion of investment in fixed assets } \\
\text { of urban landscaping public facilities } \\
\text { construction in GDP }\end{array}$ & 1.000 & l \\
\hline & Per capita green area of Park & 0.029 & 0.923 \\
\hline & $\begin{array}{c}\text { The comprehensive utilization rate of } \\
\text { industrial solid waste }\end{array}$ & 0.055 & 0.852 \\
\hline
\end{tabular}

\section{Conclusions and Recommendations}

In this study, the PSR model was used to construct the evaluation index system of the ecological carrying capacity of the Greater Bay Area around Hangzhou Bay, which was composed of 17 indicators. The entropy weight method was used to objectively empower, and then the TOPSIS model and exponential smoothing method were used to analyze the ecological carrying capacity of the Greater Bay Area around Hangzhou Bay from 2006 to 2019. The spatial evolution of the ecological carrying capacity of the Greater Bay Area around Hangzhou Bay was analyzed by GIS, and finally, the driving factors of the ecological carrying capacity of the Greater Bay Area around Hangzhou Bay were analyzed. The main conclusions are as follows:

The comprehensive analysis results of pressure, state and response indicators show that the ecological pressure of the Bay Area around Hangzhou Bay tends to decrease, and the state of the ecosystem itself is also good. At the same time, the environmental governance work carried out by 
human beings has certain positive effects. From the perspective of time change of ecological carrying capacity, from 2006 to 2019, the pressure carrying capacity showed a decreasing trend overall, and it is predicted that it will still decrease in the next three years. The overall steady rise of state carrying capacity indicates that the ecosystem state has gradually improved in recent years. When the response bearing capacity and the comprehensive bearing capacity are highly overlapped, the environmental protection measures have a significant positive impact on the change of the comprehensive bearing capacity. From the perspective of spatial change of ecological carrying capacity, the ecosystem carrying capacity of the early Northwest cities is generally more ideal than that of the central and southern cities. After the government proposed to jointly plan and build the Bay Area around Hangzhou Bay, the distribution of ecological carrying capacity in the Bay Area is relatively balanced. The discharge of industrial wastewater and industrial sulfur dioxide will weaken the carrying capacity of the ecosystem while improving the sewage treatment rate and the greening coverage rate of builtup areas will have positive effects on the ecology. However, the ecological carrying capacity is only positively correlated with the proportion of fixed asset investment in urban landscaping public facilities in GDP, indicating that the annual fixed asset investment in urban landscaping public facilities greatly affects the change of comprehensive carrying capacity.

In view of the continuous negative impact of human activities on the ecosystem, the Bay Area around Hangzhou Bay should grasp the lever of economic development and environmental protection in the future, pay attention to improving the green coverage rate of urban built-up areas and strengthening the comprehensive utilization of solid waste while the economy is developing at high speed, so as to improve the environmental quality and further enhance the ecological carrying capacity. At the same time, the government should explore and establish a new model of joint prevention, joint control and coordinated development among the cities in Hangzhou Bay Area so as to achieve resource sharing and pollution co-treatment, so as to enable the balanced development of all cities and stimulate the potential of economic development in the Bay Area. Finally, the Bay Area should make full use of its resource advantages in the future, speed up the transformation of industrial structure, organically combine end treatment with source control, increase investment in Environmental Protection industries or facilities, and contain pollution sources in the cradle.

\section{References}

[1] Bian Yu, Study on Ecological Footprint of Forest Resources in Fujian and its Spatial Characteristics. Fujian Agriculture and Forestry University, 2010.

[2] Zhang Linbo, Ecological Carrying Capacity Theory and Assessment Method of Urban Ecosystem-Shenzhen as A Case Study. 2009, Beijing: China Environmental Science Press.

[3] Shen weishou et al., Study on Regional Ecological Carrying Capacity and Ecological Security. 2010, Beijing: China Environmental Science Press.

[4] Yao zhenhuan, Research on Urban Sustainable Development Based on Ecological Carrying Capacity Theory. Co-Operative Economy \& Science, 2021(14):24-25.

[5] Gao Jixi, et al., Theoretical Exploration of Sustainable Development: Theory, Method and Application of Ecological Carrying Capacity 2001, Beijing: China Environmental Science Press.

[6] LAN Lihua and Tian Yi, Theoretical Methods Research Advances of Resource Environmental Carrying Capacity. Resources \& Industries, 2020.22(04):87-96.

[7] Peng Qiuping et al., Review of Research on Environmental Carrying Capacity Evaluation Based on Index System Method. Aeronautical Computing Technique, 2020.50(04):130-134.

[8] Yue, Q., X. Wu and Y. Wang, Analysis and Evaluation of the Ecological Carrying Capacity of Liaoning Two Urban Agglomerations Based on State Space Method. Progress in Environmental Protection and Processing of Resource, PTS 1-4, 2013. 295-298: p. 2564-2568.

[9] Yue Dongxia et al., Biocapacity and Ecological Water Demand in Shule River Basin over the past 20 Years. Acta Ecological Sinica, 2019,39(14):5178-5187. 
[10] Cai Fei et al., Assessment of Ecological Carrying Capacity of Xi' an City Based on Ecological Footprint Model. Fujian Architecture \& Construction, 2021(07):48-51.

[11] Peng, B., et al., Evaluation and Prediction of the Ecological Footprint and Ecological Carrying Capacity for Yangtze River Urban Agglomeration Based on the Grey Model. International Journal of Environmental Research and Public Health, 2018. 15(11).

[12] Wang, H., et al., Assessment of the Ecological Security in the Three Gorges Reservoir Area by Using the Ecological Footprint Method. Journal of Mountain Science, 2012. 9(6): p. 891-900.

[13] Ao Lihong and Yuan hongqing, Theory and Practice of Bay Area Economic Development. 2017, Changchun: Jilin University Press.

[14] Xiong Hongbin and Han Shangxin, Evaluation of Resources and Environmental Carrying Capacity in Anhui Province Based on PSR-improved TOPSIS model. Journal of Anhui Agricultural University, 2018. 45 (02):274-281.

[15] Pi Qing et al., Environment Carrying Capacity Evaluation System and Applied Research Based on PSR Model--A Case Study of Wuhan Metropolitan Area. Science and Technology Management Research, 2016. 36(06):238-244.

[16] China City Statistical Yearbook (2006-2019). https://data.cnki.net/Yearbook/Single/N2021050059.

[17] China Urban Construction Statistical Yearbook (2006-2019). https://data. cnki.net/ yearbook/ Single/ N 2021070166.

[18] Shanghai Statistical Yearbook (2006-2019). https://data.cnki.net/yearbook/Single/N2021050059.

[19] Hangzhou Statistical Yearbook (2006-2019). https://data.cnki.net/yearbook/Single/N2021020075.

[20] Resource and Environment Science and Data Center, Chinese Academy of Sciences, Administrative Boundary Data of Prefectures and Cities in China in 2015(2015). https:// www.resdc. cn/data. aspx? DATAID $=201$.

[21] Dong zhanfeng et al., Chinese Provincial Environmental Performance Index Based on Entropy Method. Environmental Pollution \& Control, 2016.38(08):93-99.

[22] Wang Qiong et al., River Habitat Quality Assessment Based on Principal Component Analysis and Entropy Weight in Qinghe River. Ecological Science, 2017.36(04):185-193.

[23] Wang Li et al., GPS Satellite Clock Bias Prediction Based on Exponential Smoothing Method. Geomatics and Information Science of Wuhan University, 2017.42(07):995-1001.

[24] Fu Jia, Research on Prediction of Thermal Coal Price Based on Exponential Smoothing Method. Coal Economic Research, 2018.38(07):6-12.

[25] Wang Chen, Guo Wei and Zhou Luojing, Comparison of ARIMA Model and Exponential Smoothing Method in Predicting Outpatient Visits. Preventive Medicine, 2018.30(11):1152-1155. 